\title{
Development of low cost tri-cycle garden boom sprayer for fruit trees in Bangladesh
}

\author{
Md. Israil Hossain, Nusrat Jahan and M. A. Ggulandaz \\ Farm machinery \& Postharvest Process Engineering Division, Bangladesh Agricultural Research \\ Institute (BARI), Gazipur-1701, Bangladesh
}

$₫$ For any information: ask.author@journalbinet.com, Received: 16.08.17, Revised: 26.09.17;

Available online: 14 October 2017.

\begin{abstract}
A low cost robust tri-cycle garden boom sprayer has been developed in Farm Machinery \& Postharvest Process Engineering Division of BARI Gazipur and all set up installed on a tri-cycle rickshaw van. It has been further improved with flexible boom which allow spraying in tall fruit trees and evaluated for mango and litchi trees. Crop yields are reduced mainly due to attack of pests, diseases and weeds. The developed boom sprayer consists of small diesel engine, high pressure pump, pesticide tank, boom with nozzle, and tri-cycle. The chemicals are sprayed as the most effective and efficient techniques for applying small volume of spray liquid to protect horticultural crops. The boom sprayer was tested for spraying pesticide in fruit trees to produce uniform effective spray pattern using minimum amount of spray materials. The spray boom has hollow nozzle and can spray in tall tree. The effective field capacity of the sprayer was $0.3 \mathrm{ha} / \mathrm{hr}$ under 3 bars pump pressure. The average spray capacity 2.85 lit/min at 3 bar pressure. The power requirement is $4 \mathrm{~kW}$ for operating the pump. Operating cost of garden boom sprayer was Tk. 595/day and foot sprayer was Tk.1029/day, respectively (1US\$=Tk. 80.0). The entire boom assembly fixed on a rickshaw van behind the operator seat. It is safe in adverse wind condition. To facilitate convenience operation for the operator, the design of the entire controls provided near the operator hand. A transparent plastic tank was provided for clear view of pesticide status in the tank.
\end{abstract}

Key Words: Tri-cycle garden boom sprayer, horticultural crops, uniform spray, hollow nozzle and spray capacity

Cite Article: Hossain, M. I., Jahan, N. and Ggulandaz, M. A. (2017). Development of low cost tri-cycle garden boom sprayer for fruit trees in Bangladesh. Journal of Bioscience and Agriculture Research,15(01), 1255-1259. Crossref: https://doi.org/10.18801/jbar.150117.154

Article distributed under terms of a Creative Common Attribution 4.0 International License.

\section{Introduction}

Pesticides are being used for protecting crops in most developing countries due to continuous increasing demand for quantity and quality of food grains. Crop yield is reduced mainly due to attack of pests, diseases and weeds. Chemicals control is the popular method adopted for controlling most 
insects, weeds and diseases. They are applied in varying amounts, depending upon the type and concentration of active ingredients. Common pest problems in fruit trees are the red mites and scale which can be suppressed by dormant oil spraying. Spraying of insecticide will be necessary to control these and other insects during the growing period (Sprayer Deport, 2016). Appropriate sprayer is needed to apply dormant oil effectively for fruit trees.

Bangladesh is mainly operated knapsack sprayers, power duster, and foot pump sprayer. Appropriate machinery and mechanization enables conservation of applied inputs by precision in metering and ensuring better distribution, minimizing the level of costly amount required for the best output and reducing of losses of applied inputs. The mechanization reduces the unit costs for the production by the high level of productivity and by input conservation. Recent times scientists developed new sprayer which reduced average pesticide use 46-68 \% and average cost savings of $\$ 230$ per acre for ornamental nurseries. The savings may more higher for fruit crop production (Durham, 2016). Due to small and scattered farms, the farmers mainly depend upon knapsack sprayer for field crop and foot pump spray for fruit trees. Manual spraying is uneven, produced uneven pressure and some times health hazards. It is time consuming, laborious and slow. Alam (2000) reported that there is a chance of overlap or missed area during operation of knapsack sprayer. Maintaining a constant walking speeds and constant distance between nozzle and plant tops ensure uniform distribution of spray materials per unit time. Varying the walking speed or distance between the nozzle and plants tops causes uneven distribution of spray materials. The distance between the nozzle and top of the plants should be maintained at around $30 \mathrm{~cm}$ (IRRI, 1988). Using the recommended pressure, flow rate, nozzle height, and spray swath are necessary for even spraying and getting maximum benefit from pesticide application.

Recent days, farmers are showing interested growing horticultural crops due to high value, less risk, and easy marketing. The fruit garden are expanding in the district of Dinajpur, Rajshahi, Ishwardi region, and hill areas of Bangladesh. and currently, total fruit production is 4.7 Million metric ton (BBS, 2015). Generally farmers use foot pump sprayer for fruit garden. It is time consuming, uneven sparing, costly, and tedious job. For easily and conveniently pesticide application, a study has been taken to develop a low cost tri cycle boom sprayer for fruit trees. The experiment was conducted to develop a power garden boom sprayer for fruit trees and all accessories set up on a tri-cycle van, test and evaluate the performance of boom sprayer for horticultural crops and to compare the cost of operation with manual foot pump sprayer.

\section{Materials and Methods}

Description of garden boom sprayer: A robust power boom sprayer was fabricated in Farm Machinery \& Postharvest Process Engineering Division of Bangladesh Agricultural Research Institute (BARI) 2015 and it is further improved with flexible boom height in 2016-17. The sprayer consisted of a small diesel engine, transparent pesticide tank, spray pump, spray boom, tank support wheel with tread adjustments. The chemical tank is a plastic tank of 150 litre capacity. The tanks were placed on a common tri-cycle rickshaw van. All components of boom sprayer was set up on the van (Figure 01). This facilities the bracket to move in both the vertical and horizontal plane. Square size $500 \times 25 \times 6$ $\mathrm{mm}$ were bent and bolted to the main frame so that it secured the tank without any slippage. The tank was interconnected using $40 \mathrm{~mm}$ PVC pipes and attached to

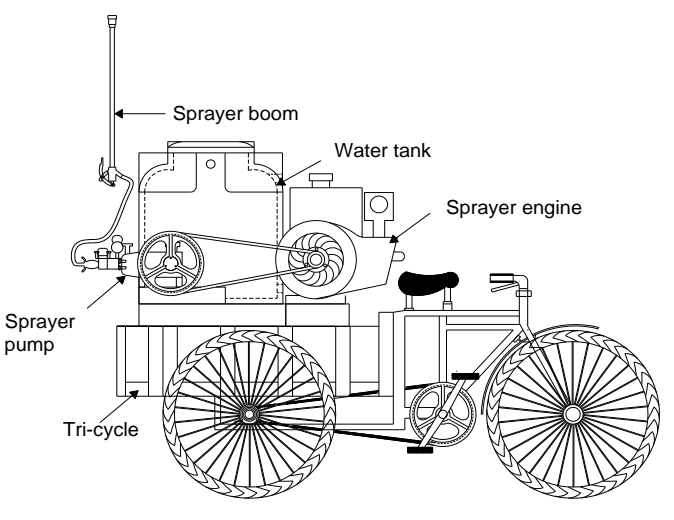

\section{Figure 01. Tri-cycle power garden boom sprayer} the inlet of the spray pump. A hole of $110 \mathrm{~mm}$ diameter was drilled on the pesticide tanks and fixed with PVC male threaded adapter and capped for easy filling of pesticide. A diesel operated sealed pump was attached with special frame of trailer for a high volume sprayer with hollow cone nozzle having field application rate of 2.9-3.9 lit/min. For design purpose the maximum application rate was taken as 3.5 lit/min. The pump, engine, strainer, pressure gauge was fitted near the seat of the operator and the dial gauge of pressure easily visible to operator. Power to the pump was taken from 
the diesel engine. A $40 \mathrm{~mm}$ diameter flexible hose was used as suction to transmit the spray liquid from the tank to the pump. On the discharge side the hose was provided as a by-pass with a control valve to drain off the excess pesticide back to the tank. A pressure gauge of 0-5 bar was mounted after the by-pass to monitor the pressure in the nozzle. The boom length was chosen as on either side of the two wheel tractor. The nozzles were mounted on a flexible hose of $6 \mathrm{~mm}$ internal diameter and were clamped to a rigid pipe.

The spacing between nozzles on the boom can be adjusted by means of adjusting the clamps. The boom was attached on a tri cycle. The boom was tied using stay chain to the vertical frame to keep them in position while spraying. Provision was also made to fold the spray boom while in transport. The spraying system requires stability for better maneuverability in the field. Adding 150 lit capacity pesticide tank, on the back side of the operator, just like a trolley for transportation. Therefore, double pneumatic support wheels with provision of tread adjustments were provided to increase or decrease the tread width in alignment with that of tractor wheels.

\section{Table 01. Specification of tri-cycle garden boom sprayer}

\begin{tabular}{ll}
\hline \multicolumn{1}{c}{ Name of component } & \multicolumn{1}{c}{ Specifications } \\
\hline Power source & $5.5 \mathrm{Hp}(4 \mathrm{~kW})$ Diesel engine \\
Type of pump & Piston pump, Automatic \\
Width of boom & $1.0 \mathrm{~m}$ \\
Boom discharge & Average 2.9 lit./min at 3 bar pressure \\
Number of nozzles & 2 \\
Type of nozzle & Hollow cone \\
Nozzle spacing & $500 \mathrm{~mm}$ \\
Tank capacity & 150 lit. \\
\hline
\end{tabular}

A telescopic arrangement to increase or decrease the horizontal width was provided by inserting two square sections of size $270 \times 50 \times 50 \mathrm{~mm}$ made of angle iron of size $50 \times 50 \times 6 \mathrm{~mm}$ on each side. Two angle bar with different holes were placed backside of the pesticide tank supporting the booms. There are adjustments for high and low the spray height with an interval of $25 \mathrm{~mm}$. The support wheels were attached to the telescopic sections through flange plates of size $175 \times 100 \times 6 \mathrm{~mm}$. The flange facilitated fixing the wheel mounting in such a way that the wheels could be oriented outwards or inwards with respect to the support frame. The specification of the tri cycle garden boom sprayer is given in Table 01 . The boom sprayer was tested for pesticide application in the mango

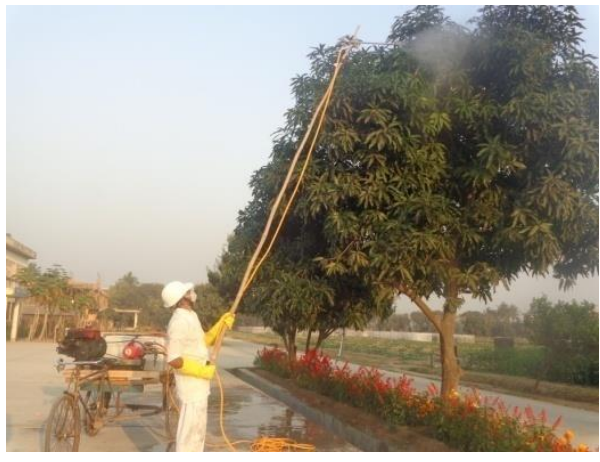

Figure 02. Operational view of garden boom sprayer. and litchi tree of Dinajpur and Gazipur (Figure 02) of Bangladesh . Data were collected, (i) flow rate of nozzle (ii) travel speed of the sprayer (iii) spray pressure (iv) area coverage per unit time (v) cost of operation.

Calibration of boom sprayer: Tri cycle operated boom sprayer is calibrated to understand and fix up the application rate of pesticide for maximum benefit. It is calibrated in an open floor of FMPE BARI Gazipur. Fresh water is used measure the discharge rate of nozzle. Varying the spraying pressure, delivered water from each nozzle collected in a container and record the time by a stop watch. It is repeated varying pressure until the desired rate occurred.

Calculate target discharge rate : The following formula calculates the number of gallons per minute (GPM) that must be delivered by boom sprayer nozzles for the application rate to be corrected. 
$\mathrm{GPM}=\frac{\text { GPA X MPH X W }}{5940}$

Where,

$\mathrm{GPA}=$ Gallons per acre from product label

$\mathrm{MPH}=$ Sprayer speed, in miles per hour

$\mathrm{W}=$ Spacing of nozzle on boom, in inches

\section{Results and Discussion}

Evaluation of boom sprayer was conducted in laboratory condition for varying pressure of 2, 3 and 4 bars on the sprayer pump operated by rear mounted boom sprayer provided with Hollow jet nozzle. Figure 03 shows the relationship between pressure and nozzle discharge. The relationship between pressure and discharge is

$Y=0.035 X+2.82$

Where,

$\mathrm{Y}=$ discharge in $\mathrm{ml} / \mathrm{min}$

$\mathrm{X}=$ pressure in bar

Table 02 illustrates the relationship between pressure and cone angle, where cone angle is the angle subtended at the orifice by the edge of the spray pattern. This angle is

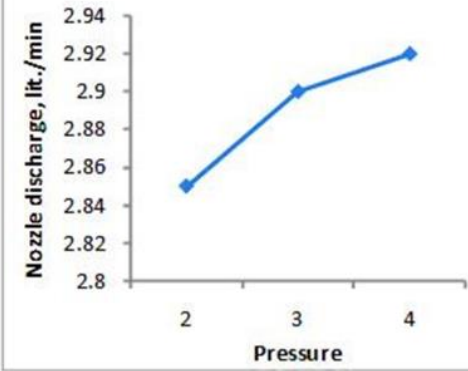

Figure 03. Relationship between pressure and nozzle discharge. formed due to tangential axial velocity component of the fluid coming out of the nozzle (Table 03). Cone angle increases with an increase in pressure. The nozzle spray distribution from the boom for two nozzles was studied by keeping them $500 \mathrm{~mm}$ apart $550 \mathrm{~mm}$ above the surface. The spray deposition at $550 \mathrm{~mm}$ nozzle height and $500 \mathrm{~mm}$ nozzle spacing for 3 bar pressure was observed to be uniform on both sides for the two nozzles of the spray boom.

Table 02. Relationship between pressure and cone angle of hollow jet nozzle

\begin{tabular}{ccc}
\hline Pressure (bar) & Width of spray $(\mathrm{mm})$ & Spray cone angle \\
\hline 2 & 575 & $104^{0}$ \\
3 & 600 & $108^{0}$ \\
4 & 615 & $113^{0}$ \\
\hline
\end{tabular}

The discharge rate of each nozzle in the boom for operating pressure of 2, 3 and 4 bar were observed and tabulated in Table 03. It was concluded that, discharge rate of the nozzle in the boom was directly proportional to the operating pressure. Average discharge rate of $2.91 \mathrm{lit} / \mathrm{min}$ was recorded for $3 \mathrm{bars}$ followed by $2.83 \mathrm{lit} / \mathrm{min}$ and $3.37 \mathrm{lit} / \mathrm{min}$ discharge corresponding pressure 2 bar and 4 bars, respectively.

Table 03. Discharge rate of spay nozzle of boom sprayer

\begin{tabular}{clllc}
\hline Pressure (bar) & \multicolumn{3}{c}{$\begin{array}{c}\text { Nozzle discharge (l/min) } \\
\text { Replication }\end{array}$} & $\begin{array}{c}\text { Average discharge } \\
\text { (l/min) }\end{array}$ \\
\cline { 2 - 4 } & 1 & 2 & 3 & \\
\hline 2 & 2.81 & 2.83 & 2.84 & 2.83 \\
3 & 2.92 & 2.91 & 2.92 & 2.91 \\
4 & 3.3 & 3.3 & 3.37 & 3.32 \\
\hline
\end{tabular}

Average effective capacity of the boom sprayer was $0.3 \mathrm{ha} / \mathrm{hr}$ at the pressure 3 bar. Total time required for spraying one hectare land was $3.3 \mathrm{hrs}$. Manual foot pump sprayer can cover only 0.1 
ha/hr which required 10 hours for one hectare land (Table 04). Considering the high pressure of boom sprayer, it is much easier for spraying tall fruit tree.

Table 04. Comparison of performance of boom sprayer and manual knapsack sprayer

\begin{tabular}{ccc}
\hline Item & Boom sprayer & Foot pump sprayer \\
\hline Effective field capacity, ha/hr & 0.3 & 0.1 \\
Time required per ha, hr & 3.3 & 10 \\
\hline
\end{tabular}

Cost of boom sprayer and knapsack sprayer operation were cal calculated on the basis of purchase price, depreciation, and annual use of the sprayers (Table 05). Operating cost of garden boom sprayer was Tk. 595/day and foot sprayer was Tk.1029/day, respectively (1 US\$=Tk. 80.00).

Table 05. Cost of operation between boom sprayer and manual knapsack sprayer

\begin{tabular}{lc}
\hline Name of sprayer & Cost of operation (Tk.)/day \\
\hline Tri cycle garden boom sprayer & 595.0 \\
Foot pump sprayer & 1029.0 \\
\hline 1 US \$ = BDT 80.00 &
\end{tabular}

\section{Conclusion}

The tri cycle garden boom sprayer can be used for mango and litchi tree as well as any fruit trees. The effective capacity of the boom sprayer was $0.3 \mathrm{ha} / \mathrm{hr}$ for a mango trees. The performance of the tri cycle boom sprayer was satisfactory at the pressure of 3 bars and can be adopted by the farmers for spraying fruit tree as it saves the cost and time of operation. The operational cost of garden boom sprayer was Tk. 595/day and the traditional foot pump sprayer was Tk.1029/day, respectively (1 US\$= Tk.80.0). The garden boom sprayer is safe to handle chemical. It can be fabricated easily within the short period of time and can be used as custom hire services.

\section{References}

[1]. Alam, M., Bell, M. A. and Mortimer, A. M. (2000). Targeting farmer spray applications for improved safety and uniformity. International Rice Research Conference, IRRI, Phillipines. p. 223.

[2]. BBS (2015). Year book of agricultural statistics. Bangladesh Bureau of Statistics.

[3]. Durham, S. (2016). New sprayer technology reduces pesticide use. Retrieved 16 September 2017 from https://www.ars.usda.gov/is/pr/2016/160211.htm.

[4]. IRRI (1988). Operating a knapsack sprayer, RP3-18. Rice production skills development series. p. 9

[5]. Sprayer deport (2016). Time for dormant oil application to fruit trees. http://info.sprayerdepot.com/topic/fruit-tree-sprayers 